\title{
ECOLOGIA POLÍTICA, MOVIMENTOS AMBIENTALISTAS E CONTESTAÇÃO TRANSNACIONAL NA AMÉRICA LATINA
}

\author{
Carlos R. S. Milani*
}

\begin{abstract}
Os anos pós-Guerra Fria possibilitam uma renovação do debate latino-americano sobre as tensões entre meio ambiente, ética e política internacional. Defensores da idéia de que as relações internacionais emergem exclusivamente da interação entre entidades políticas soberanas e independentes contrapõem-se aos que sustentam a centralidade na agenda ecopolítica de muitos outros atores para além do Estado. Ou seja, os princípios da soberania incondicionada e da não-ingerência - ordenadores tradicionais do sentido das "relações internacionais" - são questionados pela crescente transnacionalização das reivindicações, por redes e movimentos ambientalistas, de condutas éticas e responsáveis no campo ambiental. É com base nesses pressupostos que o presente artigo se estrutura em duas partes: (1) uma discussão sobre o processo de internacionalização da problemática ambiental e das tensões contemporâneas entre meio ambiente, ética e política internacional na América Latina; (2) uma análise dos questionamentos trazidos pelo campo do ambientalismo latino-americano operando no seio da contestação transnacional do Fórum Social Mundial.

PALAVRAS-CHAVE: ecologia política, movimentos ambientalistas, contestação transnacional, relações internacionais, América Latina.
\end{abstract}

\section{INTRODUÇÃO}

Os primeiros debates mais politizados e críticos sobre meio ambiente, na agenda internacional, datam do final dos anos 1960 e início dos anos 1970, culminando com o marco histórico que representou a celebração da Conferência das Nações Unidas sobre o Meio Ambiente Humano (Estocolmo) em 1972. Antes disso, a representação social sobre o problema ambiental era influenciada, sobretudo, por normas de conservação e preservação de ecossistemas (mares, subsolos, Antártica, zonas desnuclearizadas) e de proteção de espécies ameaçadas de extinção (aves migratórias, mamíferos aquáticos). A partir de 1972, natureza, ciência e política começaram gradativamente a constituir uma agenda comum (Latour, 1999), provocando um diálogo entre a urgência da proteção ambiental e a necessidade do desenvolvimento.

* Professor de Pós-Graduação da Escola de Administração da Universidade Federal da Bahia. Pesquisador CNPq e Coordenador do Laboratório de Análise Política Mundial (LABMUNDO).

Av. Reitor Miguel Calmon, s/n - Vale do Canela. Cep: 40110-903 - Salvador - Bahia - Brasil.cmilani@ufba.br
Essa agenda tem sido permeada por uma retórica do poder dos discursos institucionais (defesa da soberania incondicionada, princípios de não-ingerência, representação política formal) e pela função de denúncia e monitoramento dos discursos militantes (catástrofes ambientais, acidentes petroquímicos, expertise ambiental, produção de contra-informação). Ambos os discursos marcaram fortemente o início do processo de internacionalização da problemática ambiental.

A partir dos anos 1980, notadamente no que diz respeito a temas relativos a aquecimento global, proteção da camada de ozônio e da biodiversidade, assim como desflorestamento e desertificação, o meio ambiente se converteu em um tema central na agenda mundial das negociações políticas e econômicas. A crise ambiental deixou de ser um item setorial da pauta política e passou a integrar a agenda mais ampla de segurança coletiva (Barros-Platiau, 2006; Milani, 1999). No período situado entre Estocolmo (1972) e a Conferência das Nações Unidas sobre o Meio Ambiente e o Desenvolvimento (Rio de Janeiro, 1992), consolidou-se o consenso, agora também corroborado 
pela expertise científica, de que as intervenções humanas sobre a natureza têm sido de tal dimensão, que provocam modificações irreversíveis para a estrutura e o funcionamento dos ecossistemas (desde o nível do organismo, populacional, das comunidades, paisagens, até o nível da biosfera), donde o caráter de urgência política de uma ação preventiva fundada no princípio ético e político da precaução.

Hoje há, portanto, um conhecimento acumulado e uma consciência mais ampla acerca dos limites impostos pela natureza, presentes nos discursos e modos de ação política dos atores estatais e operadores não estatais das relações internacionais, tanto no plano da ecopolítica mundial quanto no âmbito regional latino-americano. É da dialética entre a evolução lenta (porém direcionada) no campo dos ideários, da consciência coletiva e das subjetividades, de um lado, e os efeitos materialmente visíveis da crise ambiental (por exemplo, nas suas relações com a matriz energética, o modelo econômico, os padrões de consumo, a geopolítica ou a própria sobrevivência da humanidade), de outro, que resulta a importância crescente adquirida pelo problema ambiental-ecológico na definição das estruturas de poder das relações internacionais. O meio ambiente interfere na política regional latino-americana como representação (subjetividades e identidades, afiliações políticas, discursos) e, ao mesmo tempo, como dimensão material e territorial estruturante da geopolítica das trocas e das alianças entre sociedades, mercados e governos (Rosa; Dietz, 1998; Prades, 1999). ${ }^{1}$

É verdade que, no plano das idéias e crenças, a revolução ecológica foi anterior à tomada de

${ }^{1}$ Rosa e Dietz (1998) tratam das diferentes lentes teóricas para o entendimento das relações entre mudanças climáticas e sociedades, reconhecendo que tais transformações impactam diretamente na sustentabilidade dos ecossistemas e em todas as formas de organização social (humanas e não humanas). Os autores identificam duas orientações sociológicas na compreensão das relações entre mudanças climáticas e sociedades: a orientação por eles chamada de neo-realista que tem fundamentação materialista e pressupõe um mundo objetivo independente da percepção dos atores humanos e sociais; uma outra orientação construtivista, que parte dos marcos interpretativos da crise provocada pelas mudanças climáticas. consciência política, econômica e institucional. Os movimentos pacifistas e contrários ao uso da energia atômica, as denúncias dos efeitos nefastos da "revolução verde" e do uso de pesticidas (agrotóxicos) na agricultura, entre outros aspectos, despertaram o primeiro grito dos atores de protesto da sociedade civil latino-americana. A estrutura política, em contraposição, foi fortemente instada pelo alarme do Clube de Roma, quando da publicação do célebre Relatório Meadows (The limits to growth) em 1972. Ao introduzir temas relativos à ameaça da penúria e à degradação do meio ambiente, esse relatório pôde criar o choque político desejado nos meios institucionais: as dimensões ecológicas, econômicas, demográficas e políticas da crise corroboraram o surgimento de uma problemática nitidamente global (Andrade; Taravella, 2008; Caldwell, 1984; Milani, 2000). Na América Latina, o grito dos movimentos indígenas e dos seringueiros, o surgimento dos movimentos ecologistas e dos primeiros partidos verdes, o movimento dos atingidos por barragens (MAB), o "boom" das organizações não-governamentais nos anos 1990, bem como as redes anti-alterglobalistas do Fórum Social Mundial, têm levantado, de modo heterogêneo e não unificado, a bandeira da proteção ambiental e de reforma em profundidade do sistema econômico (Leis, 1991; Martinez-Alier, 2007; Milani, 1998).

Particularmente no campo disciplinar das Relações Internacionais, os anos Pós-Guerra Fria têm possibilitado, ainda que de maneira errática e não homogênea, uma renovação do debate sobre as tensões entre meio ambiente, economia global e política internacional. Se, por um lado, alguns autores defendem a idéia de que o sistema internacional emerge exclusivamente da interação entre entidades políticas soberanas e independentes, por outro, parece-nos inevitável reconhecer que a ordem ecopolítica mundial também se compõe de muitos outros atores para além dos Estados nacionais. Ou seja, o princípio de uma soberania incondicionada, o exercício da autoridade estatal restrita sobre o território nacional e a defesa da não-interferência - ordenadores tradicionais do 
sentido das "relações internacionais" - são questionados pelos processos de globalização, pela internacionalização do problema ambiental e pela crescente reivindicação, por redes e movimentos ambientalistas, de condutas éticas e ações responsáveis na solução política dessa crise. As relações internacionais se construíram em torno de Estados nacionais soberanos (donde a idéia de um sistema interestatal), fazendo com que se naturalizasse a hipótese de que a política não existiria fora desse sistema. Essa naturalização do sistema interestatal como lócus exclusivo da política internacional não permite, porém, entender as diferentes formas de violação da soberania westfaliana, tais como as intervenções militares, a ingerência humanitária, o controle direto do território nacional alheio, restrições à soberania nacional, tutela internacional, além da movimentação do capital econômico - transnacional desde a sua origem (Badie, 1995; Cairo, 2006; Smouts, 2004).

A soberania nacional, como elemento norteador das relações entre sociedades e Estados, vê-se assim interpelada e desafiada pelo princípio de responsabilidade ambiental, cujos limites em termos de regulação não coincidem, freqüentemente, com as fronteiras nacionais. Os problemas ambientais, transfronteiriços por natureza ou transnacionalizados por vias da ação política dos movimentos e redes ambientalistas, renovam a agenda política na América Latina, fazendo convergir, não sem confrontos, os padrões éticos, as normas políticas e as exigências econômicas na regulação dos comportamentos dos Estados e dos agentes privados (empresas e indivíduos). É evidente que essa convergência entre capital e ecologia não ocorre sem obstáculos importantes. No presente artigo, serão analisados alguns dos repertórios políticos e demandas dos movimentos ambientalistas na América Latina, sobretudo aqueles inseridos na onda anti-alterglobalista do Fórum Social Mundial. O artigo constará de duas partes principais: (1) uma discussão sobre o processo de internacionalização da problemática ambiental e das relações e tensões contemporâneas entre meio ambiente, economia global e política internacional (com ênfase na América Latina); e (2) uma análise de alguns dos questionamentos críticos trazidos pelo campo do ambientalismo latino-americano, que opera no seio da contestação transnacional do Fórum Social Mundial.

\section{O MEIO AMBIENTE COMO PROBLEMA TRANSNACIONAL NA AMÉRICA LATINA: a visão da ecologia política}

No quadro atual das mutações da política latino-americana, a problemática do meio ambiente complexifica as tensões entre os princípios de soberania e de responsabilidade no mundo dos Estados, mas igualmente as relações entre os interesses particulares dos agentes individuais e as necessidades macro-coletivas de justiça social e prudência ecológica. As ameaças que pesam sobre o meio ambiente (fragmentação de ecossistemas, extinção de habitats, introdução de espécies exóticas, ameaça a identidades indígenas) e a necessidade de construir ações coletivas a fim de prevenilas ou restaurá-las implicam uma reformulação de questões políticas e éticas essenciais, re-introduzindo, na linguagem normativa da política latinoamericana, o debate sobre o bem comum. No caso da proteção da sociobiodiversidade, por exemplo, as tensões tornam-se evidentes ao colocarem em diálogo duas cosmovisões bastante distintas quanto aos mecanismos de regulação dos saberes e das práticas associados à diversidade natural: de um lado, a solução apontada pelo regime de patentes (propriedade intelectual); de outro, a demanda por alguns movimentos (sobretudo indígenas e ambientalistas) de reconhecimento da particularidade do estatuto de bem comum para os saberes tradicionais e autóctones (Dias; Costa, 2008; Rezende, 2007).

Parafraseando Sousa Santos (2006), a crise ambiental engendra zonas de contato intercultural em que se explicitam conceitos e significados quanto à definição dos bens a proteger, assim como práticas referentes à explicitação dos conflitos e à implementação de mecanismos de proteção ou res- 
tauração ecológica. Nas zonas de contato, entram em diálogo visões diferenciadas sobre o meio ambiente. Do ponto de vista normativo, a diversidade não é assim considerada como fator de fragmentação ou isolamento, mas como elemento instigador de um sentido de "incompletude recíproca” e de solidariedade, condição sine qua non para a efetivação do diálogo intercultural (Sousa Santos, 2006).

A problemática do meio ambienteé, nesse sentido, um dos fatores que influenciam a reacomodação da ordem mundial contemporânea em diversos níveis, porquanto alude, concomitantemente, a uma maior complexidade dos processos ecológicos (efeitos sistêmicos das alterações climáticas, por exemplo), mas também porque participa do duplo jogo das regulações internacionais por solidariedades (ações concertadas de agentes sociais e Estados) e pelo mercado (interdependência econômica). Como lembra Brenton (1994), é evidente a importância do problema ambiental na reflexão sobre a ordem política contemporânea, tendo em vista que a dialética entre os interesses particulares e a possibilidade de uma ação coletiva impõe uma delicada agenda de negociações entre os atores públicos e privados, individuais e coletivos.

Uma vez que apresenta constrangimentos claros à expansão sem limites do modo capitalista de produção, a crise ambiental está integrada à ordem política da atualidade, desconstruindo numerosos mitos relativos ao progresso tecnológico, à eficiência econômica e ao crescimento sem riscos. São recolocados em debate postulados da economia neoclássica, mas também da análise marxiana clássica. No campo da economia neoclássica, a economia ecológica (Costanza, 1991; Daly; Cobb, 1989) passa a considerar a degradação ambiental como externalidade negativa. A solução do problema ecológico implica a internalização dos custos externos negativos na equação econômica do desenvolvimento, sendo necessário atribuir valores monetários aos recursos e serviços ambientais. Como lembra Martínez-Alier (2007, p.45):

Os economistas ecológicos questionam a sustentabilidade da economia devido aos impac- tos ambientais e a suas demandas energéticas e materiais, e igualmente devido ao crescimento demográfico. As pretensões de atribuir valores monetários aos serviços e às perdas ambientais, e as iniciativas no sentido de corrigir a contabilidade macroeconômica, fazem parte da economia ecológica.

Isso significa que os economistas ecológicos buscam modelar as interações entre a economia e o meio ambiente, utilizando instrumentos de gestão dos mais diversos, entre os quais a avaliação ambiental integrada, o cálculo da capacidade de carga e de resiliência, a análise dos riscos e das incertezas e a contabilidade do capital natural. De regra, não há preocupação, no uso de tais ferramentas, quanto aos limites éticos e aos conflitos de natureza distributiva que os mecanismos de regulação pelos mercados podem suscitar. Por exemplo, aos bens naturais que não apresentam valor econômico direto pode ser atribuído um preço fictício (shadow price), permitindo, desse modo, a sua integração na lógica do crescimento econômico.

No que diz respeito à análise marxiana, contrariamente ao que afirmam Chesnais e Serfati (2003), defendemos aqui a hipótese de que a crise ecológica, do ponto de vista normativo e empírico, põe em xeque as condições de reprodução e de funcionamento do capital, ao destruir ou danificar gravemente o ambiente natural. É evidente que a exaustão da natureza e a gestão de recursos naturais raros podem ser transformadas em campos de valorização do capital e mercados de acumulação portadores de novos rendimentos para proprietários e acionistas. O capitalismo avançado engendrou direitos de propriedade sobre elementos vitais (ar, água, solo, biodiversidade, saberes tradicionais) ao converter bens livres ou bens comuns em esferas de valorização, como no caso da teoria do capital natural e na definição de mercados ad hoc que gerem os direitos de poluir. A "re(in)volução verde", por exemplo, foi, sobretudo, um formidável vetor de exportação de fertilizantes e inseticidas produzidos pelos grandes grupos da indústria química, tendo contribuído para aumentar a estrutura de desigualdades entre os camponeses de muitos países latino-americanos (Chesnais; Serfati, 2003; Martinez-Alier, 2007). No 
entanto, seguindo o pensamento de O'Connor (1994), defendemos aqui a idéia de que, ao adentrar a agenda latino-americana de negociações internacionais, a internalização dos custos econômicos provocados pela crise ecológica apresenta constrangimentos claros à reprodução do sistema capitalista no seu nível sistêmico e produtivo. A crise ambiental, ao remeter às fronteiras da sobrevivência humana e à interdependência complexa entre sociedades e modelos de produção, decomposição e consumo, desvela os limites do sistema produtivo atual. ${ }^{2}$

Além disso, para além das relações econômicas no nível sistêmico, a crise ambiental na América Latina envolve confrontos ecológicos e conflitos distributivos, como os evidenciados na resistência dos camponeses peruanos contra a mineradora Cerra de Pasco Copper Corporation (de Nova York) desde os anos 1920, ou na contestação aos modelos de desenvolvimento para a Amazônia exercida pelo sindicato dos seringueiros liderados por Chico Mendes no Brasil dos anos $80 .^{3}$

${ }^{2}$ Concordamos com O'Connor (1994), um dos fundadores da revista Capitalism, Nature, Socialism, o qual afirma a necessidade de enriquecer a análise marxista para compreender a crise ecológica. Hoje, o capitalismo se confrontaria, segundo o autor, com uma segunda contradição (a primeira seria a superprodução de mercadorias e superacumulação de capital), situada no âmbito mais amplo das condições de produção (incluindo os meios de comunicação, as infra-estruturas, as condições pessoais de produção do trabalhador, além das condições físicas e ambientais). Um dos tenores da ecologia política socialista e crítica, James $\mathrm{O}^{\prime}$ Connor, defende a idéia de que a crise ecológica nos remete a um conflito distributivo novo, donde a necessidade de vincular a exploração dos dominados pelos possuidores de riqueza e a destruição da natureza e da biosfera. O autor busca superar, assim, uma leitura produtivista do trabalho de $\mathrm{K}$. Marx e F. Engels que foi realizada durante décadas.

${ }^{3}$ Martinez-Alier (2007, p.93 e seq.) lembra que a mineração no Peru esteve, durante muito tempo, dominada pela Corporação Cerro de Pasco, até que, na década de 1960, a extração de cobre se deslocou para o sul do Peru, onde o minério é explorado a céu aberto - gerando sedimentos, deteriorando a água em regiões onde os recursos hídricos são escassos e poluindo o ar com o dióxido de enxofre das fundições. Hoje, a Southern Peru Copper Corporation, cuja fundição foi construída em 1969, que explora o minério, constitui uma das dez maiores produtoras de cobre no planeta e, desde 2005, depois da aquisição da empresa por um grupo mexicano, passou a chamar-se apenas Southern Copper Corporation. Para uma introdução à ecologia política como campo, ver o capítulo 4 de Martinez-Alier (2007), além dos periódicos Journal of Political Ecology (Estados Unidos), Ecologie et Politique (França), Ecología Política (Espanha), Capitalism, Nature, Socialism (fundado por James O'Connor e Barbara Laurence).
Ou seja, o ativismo ambiental não se explica tãosomente a partir da evolução de uma consciência ecológica, mas é, nesse caso, reflexo da combinação desigual de fatores tais como a localização dos impactos ambientais, as possibilidades reais de solução tecnológica acessível e a incerteza das ameaças. Isso significa que, nos países latino-americanos, a desigualdade também se refere a uma desigual incidência dos danos ambientais e da crise ecológica. Como lembra Acselrad et alii (2004), a demanda por justiça ecológica não se restringe à solidariedade intergeracional (entre as gerações presentes e futuras), mas traz o conflito entre natureza e economia para as relações sociais de hoje. Na perspectiva de Martínez-Alier (2007), há algo de universal nas distintas lutas por justiça ambiental que diz respeito ao nexo entre lutas por distribuição e demandas por reparação de danos ecológicos. Esse seria o substrato filosófico fundamental da ecologia política, como sublinha Martínez-Alier (p. 113):

Por distribuição ecológica são entendidos os padrões sociais, espaciais e temporais de acesso aos benefícios obtidos dos recursos naturais e aos serviços proporcionados pelo ambiente como um sistema de suporte da vida. Os determinantes da distribuição ecológica são em alguns casos naturais, como o clima, topografia, padrões pluviométricos, jazidas de minerais e a qualidade do solo. No entanto, também são claramente sociais, culturais, econômicos, políticos e tecnológicos.

A ecologia política faz sentido no contexto latino-americano porque parte do princípio de que os problemas ambientais não afetam a todos os indivíduos e grupos sociais uniformemente, além de reafirmar que a concentração de riqueza é também resultado de processos de controle sobre determinados recursos ambientais. Por exemplo, em vários países latino-americanos, os camponeses são obrigados a cultivar solos com declives (causando maior erosão das encostas), porque a terra do vale é, em sua maioria, propriedade dos latifundiários; a pobreza rural também tende, em muitos desses países da região, a intensificar a coleta de lenha em terras áridas e a utilização do esterco como combustível, o que traz efeitos negativos para a fertili- 
dade do solo; no Equador (por meio das organizações Acción Ecológica e Fundación de Defensa Ecológica, por exemplo) e no Brasil, a expansão da carcinicultura em regiões de mangue, geralmente terras públicas por se situarem em zonas de marés, ${ }^{4}$ tende a expulsar populações pobres que tiram seu sustento da exploração dos manguezais (Martínez-Alier, 2007). Ademais, a ecologia política evidencia que os conflitos ambientais ocorrem em diversas escalas, apresentando origens no plano interno e externo das fronteiras do Estado nacional. No Brasil, a expansão do cultivo dos transgênicos, por exemplo, resulta, sobretudo, de pressões externas, ao passo que o agribusiness da soja e a produção de alimentos põem em relação interesses tanto nacionais quanto internacionais (Acselrad, 2004).

A crise ecológica transforma igualmente, no plano político, a identidade dos sujeitos e a ação estratégica dos agentes, re-situando os modos de organização da política em termos de redes, de horizontalidade da decisão e de fluidez organizacional (Comolet, 1991; Deleage, 1992). A crise ambiental evidencia um sujeito social complexo que, dotado de um “pensamento ecologizado” (pensée ecologisée), o qual ultrapassa diferentes fronteiras (territórios, disciplinas, setores), posiciona-se à margem ou além das formas clássicas de afiliação política individual e coletiva (classe social, nação). Quando os movimentos sociais do campo exigem a manutenção de suas condições de vida e a conservação do meio ambiente, estão também expressando uma tomada de consciência política acerca

${ }^{4}$ As zonas de mangue (manguezais) são, de regra, outorgadas pelos governos para o cultivo do camarẫo via concessões privadas, gerando uma lógica de criação de cercas (enclosures) e privatização de bens comuns, geralmente explorados por populações ribeirinhas. A produção comercial do camarão é apoiada pelo Banco Mundial, entre outras instituições, como estratégia que visa a impulsionar exportacões não-tradicionais. Essa estratégia é conhecida mais amplamente como "Revolução Azul”, que industrializa e capitaliza a nova fronteira ecológica que representam os recursos hídricos e marinhos. A Revolucão Azul refere-se ao rápido desenvolvimento da aqüicultura nos últimos anos, em contraponto à Revolução Verde da alta produtividade de grãos, ocorrida a partir dos anos 50. Segundo dados divulgados pelo Earth Institute da Universidade de Columbia (coordenado pelo economista Jeffrey Sachs), entre os anos 50 e o presente, a pesca total, em águas abertas e abrigadas, quase quintuplicou, passando de aproximadamente 20 milhões para 95 milhões de toneladas métricas. da interconexão entre as destruições ecológicas e as agressões contra as condições de sua própria existência como produtores. Na América Latina, os conflitos de ordem distributiva e ambiental estão, assim, diretamente relacionados entre si. As atuais reivindicações do MST e da Via Campesina de acesso a terras e promoção de um desenvolvimento ecologicamente equilibrado ilustram tais reivindicações.

\section{O CAMPO DO AMBIENTALISMO LATINO- AMERICANO NAS REDES DO FÓRUM SOCIAL MUNDIAL}

É interessante notar, como demonstram a Tabela 1 e o Quadro 1 a seguir, que as redes e movimentos ambientalistas da América Latina representam mais de $55 \%$ do total das organizações participantes dos processos do Fórum Social Mundial que afirmam integrar a bandeira do desenvolvimento sustentável e da defesa do meio ambiente em suas lutas. Do total de 102 organizações e movimentos da América Latina e do Caribe, 80 são originárias do Brasil, 4 do Uruguai, 3 do Equador, 2 da Argentina, do Chile, Panamá, Peru e Paraguai. ${ }^{5}$ Muitas dessas organizações da contestação anti-alterglobalista contribuem para que o debate sobre as relações entre proteção do meio ambiente, ecologia política e desenvolvimento sustentável se encontre no centro das atenções do Fórum Social Mundial e suas declinações regionais e temáticas. É fundamental perceber que a natureza desse debate no seio do antialterglobalismo é bastante distinta da forma como

\footnotetext{
Essa coleta de dados concerne à participação de ONGs e movimentos ambientalistas que tenham participado do Fórum Social Mundial em 2002, 2003 e 2008 (Dia de Ação Global). Foi priorizada a identificação de informações de caráter geral: país sede da organização, ano de fundação, informações sobre a área de atuação (passível de categorização futura) e endereço eletrônico, para possível aprofundamento posterior. Em termos gerais, foram enquadradas como ambientalistas as organizações que fizeram referência a: ecologia, meio ambiente, desenvolvimento sustentável, direito ambiental, educação ambiental, sustentabilidade ecológica, justiça ambiental e proteção de recursos naturais em seus objetivos principais. Esses dados foram coletados e organizados pelo estudante de iniciação científica Davi Ribeiro Brazil (2007/2008).
} 
Tabela 1 - Organizações e movimentos ambientalistas no anti/alterglobalismo

\begin{tabular}{l|c}
\hline \multicolumn{1}{c|}{ Região } & $\begin{array}{c}\text { Número de } \\
\text { organizações e } \\
\text { movimentos }\end{array}$ \\
\hline América Latina e Caribe & 102 \\
\hline Europa & 27 \\
\hline África & 17 \\
\hline Ásia & 11 \\
\hline Oceania & 1 \\
\hline América do Norte & 7 \\
\hline Origem geográfica não identificada & 18 \\
\hline Fonte: Elaboração LABMUNDO.
\end{tabular}

evoluem as negociações intergovernamentais no seio das instituições das Nações Unidas e das agências econômicas internacionais.

Na edição de 2001 do FSM em Porto Alegre, o desenvolvimento sustentável integra o segundo eixo de discussão do Fórum, intitulado "acesso à riqueza e sustentabilidade", no âmbito do qual as oficinas temáticas discorrem acerca do controle social sobre o meio ambiente, a democratização do conhecimento científico e a privatização do saber por meio do regime internacional de propriedade intelectual. Em 2002, mantém-se o mesmo eixo de discussão, porém as oficinas enfatizam mais as relações entre tecnociência, ecologia e capitalismo; a agroecologia e os direitos de propriedade intelectual; o consumo verde e sustentável; e, finalmente, as cidades como espaços sustentáveis. Em 2003, ocorre uma mudança de eixos temáticos: o primeiro deles diz respeito ao desenvolvimento democrático e sustentável, estabelecendo uma ligação direta entre democracia, promoção do desenvolvimento e proteção do meio ambiente. No discurso anti-alterglobalista, a gestão dos recursos naturais passa necessariamente pela redefinição de mecanismos democráticos de controle social sobre o acesso aos bens e recursos.

Quando do quarto FSM em Mumbai (2004), um conjunto de movimentos e redes (Peoples World Water Forum, Asia Pacific Movement on Debt and Development, Public Citizen, Sweetwater Alliance, Council of Canadians e Cry of the Water) organizam o Fórum popular mundial das águas. Militantes reconhecidos internacionalmente (Vandana Shiva, Ricardo Petrella e Tony Clarke) participam dos debates. No âmbito do Fórum social panamanônico (nas diferentes edições de 2002 e 2003, em Belém do Pará, e de 2004, em Ciudad Guayana), militantes latino-americanos analisam o desenvolvimento sob o ângulo da soberania ecológica, da gestão sustentável e popular do território, da preservação das zonas florestais protegidas (reservas extrativistas), da segurança alimentar em relação com a produção agroecológica pelas famílias rurais, mas também debatem o tema da

Quadro 1 - Principais organizações, redes e movimentos ativas no FSM

\begin{tabular}{l|l}
\hline \multicolumn{1}{c|}{ Países } & \multicolumn{1}{c}{ Organizações, redes e movimentos (exemplos) } \\
\hline Argentina & Centro de derechos humanos y ambiente (CEDHA) \\
\hline Brasil & $\begin{array}{l}\text { Grupo de Estudos de Agricultura Ecológica; SOS Mata Atlântica; DNA Ambiental; Instituto de } \\
\text { Permacultura em Terras Secas; Articulação do Semi-Árido (ASA); Serviço Inter-Franciscano de Justiça, } \\
\text { Desenvolvimento; Rede Brasileira de Justiça Ambiental; Rede de ONGs da Mata Atlântica; Grupo de } \\
\text { Trabalho Amazônico; Instituto do Homem e do Meio Ambiente na Amazônia; Associação Gaúcha de } \\
\text { Proteção ao Ambiente Natural; Fundação Gaia; Instituto Ecoar para a Cidadania; Rede de Intercâmbio de } \\
\text { Tecnologias Alternativas; Movimento Articulado de Mulheres da Amazônia; Assembléia Permanente do } \\
\text { Meio Ambiente do Rio Grande do Sul }\end{array}$ \\
\hline Chile & Ecosistemas; Instituto Ecologia Política \\
\hline Equador & Deuda Ecológica (Alianza Sur Acreedores Deuda Ecológica), Red Agricultura Campesina y Mundialización \\
\hline México & Colectivo Ecologista Jalisco \\
\hline Paraguai & Centro de Educación, Capacitación y Tecnologia Campesina \\
\hline Uruguai & Comision Nacional en Defensa del Agua y la Vida \\
\hline Venezuela & Red de Cooperacion Amazonica \\
\hline Fonte: Elaboração LABMundo.
\end{tabular}


geopolítica da água e a gestão democrática dos recursos hídricos. ${ }^{6}$

Ademais, a partir da leitura de vários artigos apresentados na "biblioteca das alternativas" do website oficial do FSM e com base nos discursos pronunciados por militantes em diferentes edições do Fórum, ${ }^{7}$ pode-se afirmar que os antialterglobalistas criticam a institucionalização crescente do debate sobre desenvolvimento sustentável e a recuperação política das estratégias de sustentabilidade por corporações e instâncias econômicas internacionais. Um dos pontos de partida das críticas trazidas pelos anti-alterglobalistas concerne ao Relatório Brundtland "Nosso Futuro Comum" e à Agenda-21 (plano de ação da Conferência do Rio), dois dos documentos mais citados pelas agências internacionais atuantes no campo da proteção ambiental (Programa das Nações Unidas para o Meio Ambiente, Banco Mundial, UNESCO, cooperação bilateral, entre outras) e que lhes servem de fundamento filosófico e político na definição de seus programas. Ambos os documentos, resultantes do trabalho de intelectuais do Norte e do Sul (o que poderia dar uma forte impressão de diversidade na representação dos interesses), produziram uma linguagem política multilateral fundada no consenso e não na conflitualidade inerente às relações entre ecologia política e desenvolvimento econômico, proteção do meio ambiente e expansão do comércio internacional, promoção da justiça ambiental e defesa da neutralidade tecnológica, ou ainda o desenvolvimento voltado para fora (exportações) e o desenvolvimento orientado para dentro (mercado doméstico). Buscando

${ }^{6}$ A coordenação desse Fórum regional (FSPA) esteve a cargo da ONG Caritas, do Conselho Indigenista Missionário (CIMI), da Coordenação das Organizações Indígenas da Amazônia Brasileira (COIAB), da CUT, do Grupo de Trabalho Amazônico (GTA) e do Sindicato dos Escritores. O FSPA foi o primeiro fórum regional a se organizar no processo histórico do Fórum Social Mundial. Durante o segundo FSPA, mais de 10 mil pessoas se reuniram em torno do tema central: "Todos contra a ALCA".

${ }^{7} \mathrm{O}$ autor do presente artigo participou de todas as edições do FSM no Brasil e de algumas edições regionais e temáticas, tendo entrevistado lideranças e participantes (Sérgio Haddad, Iara Pietricovski, Fabio Monroy Martinez, Pedro Carrano, Chico Whitaker, entre outros líderes de movimentos e organizações na América Latina), a fim de fundamentar empiricamente sua análise sobre a contestação política transnacional. evitar as oposições e construindo pontes entre cosmovisões distintas, tais documentos incorrem quase ingenuamente na armadilha de terem produzido fórmulas vagas ou soluções que implicam aportes financeiros pouco realistas. O Relatório Brundtland, por exemplo, não atenta para os verdadeiros custos e as diferentes visões culturais do desenvolvimento sustentável.

Outro exemplo de crítica importante construída pelos movimentos ambientalistas latinoamericanos inseridos na onda anti-alterglobalista diz respeito ao não tratamento da questão central da ecologia política, no que se refere à distribuição das riquezas. Apontam os militantes e as lideranças antialterglobalistas que o Relatório Brundtland (assim como muitos dos programas desenvolvidos pelas instituições onusianas e do sistema de Bretton Woods), ao mencionar somente o crescimento da riqueza como fundamento para uma redistribuição futura, de fato, deixa de estabelecer uma distinção nítida entre os graus da sustentabilidade ecológica: a sustentabilidade forte e a fraca. ${ }^{8}$ As agências internacionais tendem a não radicalizar o debate e a optar pela segunda via, uma vez que a sua adoção é compatível com uma regulação da crise ambiental pelos mercados, sem tocar no cerne da questão política relativa às assimetrias espaciais e às desigualdades sociais. No entanto, como lembram Redclift e Sage (1998, p.499 e seq.) em relação ao papel da ideologia no debate sobre as mudanças climáticas:

Na perspectiva dos países em desenvolvimento, as questões distributivas encontram-se no coração das mudanças climáticas. [...] Na perspectiva sociológica, a eqüidade é fundamental para pensar as mudanças climáticas não somente pelas diferenças mensuráveis dos fluxos de energia e de materiais, dos níveis de consumo do-

${ }^{8}$ Como lembra Beckerman (1994), a sustentabilidade forte prioriza a preservação do meio ambiente, ao passo que a sustentabilidade fraca privilegia o apoio ao crescimento. A segunda fundamenta-se na distribuição das diferentes formas de capital (natural, manufaturado, humano, social) entre as gerações. Essa concepção não responde a algumas questões: Como comparar as diferentes formas de capital? Elas seriam fungíveis? Somente o progresso tecnológico permite a reparação de perdas de capital natural? A primeira traz para o debate dois constrangimentos a mais: Haveria formas de capital natural que não sejam passíveis de substituição? Como fazer funcionar, politicamente, o princípio de precaução nas relações econômicas? 
méstico ou das dificuldades em chegar a acordos internacionais, mas igualmente por razões ideológicas. [...] Talvez o melhor exemplo de fatores ideológicos influenciando o debate diz respeito à construção do ‘desenvolvimento sustentável' ou 'desenvolvimento verde', freqüentemente polarizada entre soluções ligadas a valores de transformação tecnológica (modernização ecológica) e mudanças culturais de cunho mais radical (ecologia profunda).

Ao contrario, os movimentos e organizações no seio do anti-alterglobalismo privilegiam o debate sobre a sustentabilidade forte, redefinindo e propondo mudanças mais ou menos profundas nas relações entre natureza, capital e sociedade (Rousset, 2002): não se trata tão-somente de saber se o ser humano poderá ainda transformar a natureza e conquistá-la, mas de dar-se conta do quão pouco os ecossistemas ainda podem suportar. A promessa dos avanços tecnológicos transformouse em ameaça, engendrando o que Jonas (1979) havia predefinido como uma "heurística do medo". Tais movimentos desafiam, no campo do ambientalismo, a adesão exclusiva ao "culto da vida silvestre" e ao "evangelho da eco-eficiência”, uma vez que abraçam os princípios da justiça ambiental e do ecologismo dos pobres. ${ }^{9}$

${ }^{9}$ Martinez-Alier (2007, p.21-39) analisa detalhadamente essas três correntes do ambientalismo contemporâneo e suas vertentes na América Latina. $O$ culto ao silvestre se caracteriza por ser, cronologicamente, a primeira escola a se desenvolver dentro do movimento e por assumir uma postura de inviolabilidade da natureza, a partir da preservação dos poucos espaços que restam no mundo de natureza intocada. Em relação à situação do sistema internacional, não apresenta uma postura de confronto direto, tendo como base científica a biologia da conservação e a manutenção de um discurso onde prevalece certa sacralização da natureza. $\mathrm{O}$ culto ao silvestre conta com grandes organizações pelo mundo como a International Union for the Conservation of Nature (IUCN) e a Worldwide Fund of Nature (WWF). No caso do evangelho da eco-eficiência, a natureza não é encarada como algo sagrado, mas como um recurso; isso em função da centralidade dada à economia por esse ramo do ambientalismo. Por fim, o ecologismo dos pobres, também denominado de justiça ambiental, caracterizase pelo seu desenvolvimento no Terceiro Mundo e tem como principal característica a percepcão da natureza como fonte de subsistência. A importância atribuída pelo autor a esse movimento decorre tanto da sua marginalidade quanto da sua tendência a não ser caracterizado ou não se autodenominar como parte do movimento ecologista. Sua principal argumentação está na relação entre o aumento do crescimento econômico e a ampliação dos problemas ambientais, principalmente em relação ao deslocamento de matérias-primas (relação entre Norte e Sul) e as áreas de despejo de resíduos. Seu desenvolvimento deu-se em função da luta de movimentos indígenas e camponeses nos países menos desenvolvidos, mas também graças à contribuição do movimento de racismo ambiental nos Estados Unidos.
Ademais, ao radicalizar o debate sobre o desenvolvimento sustentável, as redes ambientalistas latino-americanas demandam uma regulação internacional sobre os bens comuns do planeta com base em princípios éticos de solidariedade, evidenciando que a definição do sentido de sustentabilidade é uma questão política e não meramente econômica. Definir o sentido do que é sustentável envolve discutir o presente e o futuro das sociedades, pôr em diálogo distintas representações sociais do problema ambiental, rever o sentido das metas econômicas, avaliar os impactos ecológicos negativos de acordo com grupos e classes, bem como os diversos modos de conceber as relações entre natureza, mercado e sociedade.

É assim que movimentos e redes ambientalistas reivindicam uma participação política crescente na formação de opiniões públicas e nos processos decisórios, denunciando o déficit democrático das instâncias econômicas internacionais (Teivanem, 2004) e a falta de confiança nos sistemas políticos institucionais. Quer com o propósito de convencer as populações a modificarem seu comportamento em relação ao meio ambiente (por exemplo, na gestão dos resíduos sólidos, no uso de transportes coletivos ou na redução da refrigeração e da calefação), quer com o objetivo de promover transformações nos processos produtivos (e, portanto, no comportamento dos operadores econômicos), os movimentos ambientalistas questionam o status quo por meio de estratégias de visibilidade típicas do repertório moderno das ações coletivas (manifestações, petições), mas igualmente pelo viés de ações midiáticas (happenings), pelo lobby e pela produção de relatórios científicos por meio de redes profissionais e universitárias por eles mobilizadas.

As redes e movimentos interferem diretamente no ciclo de vida das políticas públicas ambientais por meio de ações que caracterizam a luta pela inclusão do tema na pauta pública (agenda-setting), a formulação, o controle ou o monitoramento de programas, além da implementação de soluções via projetos experimentais. Trata-se de movimentos associativos de um 
novo tipo, baseados no esgotamento ideológico dos partidos tradicionais e na necessidade de assumir, à esquerda como à direita, os mesmos constrangimentos da gestão da economia de mercado a ser repensada e transformada. A partir de uma estrutura organizacional em rede, eles fazem política à margem dos partidos políticos e se comportam como grupos de pressão e de contra-poder, cujos temas oferecem alternativas à ideologia econômica e às práticas políticas dominantes.

Por conseguinte, eles demandam o reconhecimento de um estatuto de competência particular na agenda ecopolítica mundial. As redes e os movimentos ecológicos latino-americanos, apesar de sua grande heterogeneidade (inclusive quantitativa, segundo os países da região, como evidencia o Quadro 1, apresentada anteriormente) e dos conflitos internos que os envolvem, também chamam a atenção para os novos estilos de vida e a busca de uma qualidade de vida fundada na auto-satisfação, para a necessidade de ruptura com o consumismo e a busca de uma nova ética no comércio (comércio justo). Eles demandam ser reconhecidos e integrados nos processos de tomada de decisão (como forma de participação política) e reivindicam um estatuto de competência técnica (contra-expertise) nas negociações intergovernamentais. É evidente que a crise do multilateralismo, as limitações do intergovernamentalismo estrito, a manutenção do unilateralismo norte-americano (exacerbado durante os oito anos do governo Bush) constituem um importante pano de fundo de legitimação de tais reivindicações. Como lembram Devin (2004), Wallerstein (2004), Della Porta e Tarrow (2005), o intergovernamentalismo encontra-se sob forte pressão política face à emergência dos atores e movimentos da contestação transnacional.

Retomando algumas das categorias de análise propostas por Milani e Laniado (2007a; 2007b), podese reiterar, resumida e esquematicamente, que o campo do ambientalismo, inserido nas redes de contestação do Fórum Social Mundial, contribui para a transnacionalização do problema ambiental graças a três ordens de fatores mais importantes, quais sejam: a articulação de escalas e territorialidade; a problematização do tempo ecológico vis-à-vis o tempo político; e a construção de identidades múltiplas.

\section{Territorialidade e articulação de escalas}

Do ponto de vista do território e da articulação das escalas, é importante notar que as mensagens políticas e as ações propostas pelos movimentos ambientalistas latino-americanos adquirem envergadura verdadeiramente transnacional. Nessa abordagem, a escala transnacional corresponde a um continuum territorial que se estende do local ao global (da menor à maior abrangência) e redefine, assim, a identidade, a estratégia e os recursos das organizações-em-rede. Da mesma forma que o capital transnacionalizado induz mudanças sistêmicas no regime de acumulação (que, gradativamente, passa de nacional e internacional a um regime global de acumulação), as redes, organizações e movimentos ambientalistas tendem a organizar-se e a constituir-se transnacionalmente. Criada em abril de 1992, a Via Campesina (VC) é um exemplo claro de rede de movimentos sociais camponeses de abrangência global, em que a temática ecológica é tratada em relação com os conflitos distributivos locais. ${ }^{10}$

O nexo local-global constrói o sentido do transnacional, porquanto, no processo de apropriação política e econômica dos espaços pelos movimentos e redes, o território da crise ecológica não é parcial nem limitado a uma escala local. O conteúdo dessa crise e sua extensão, as ameaças introduzidas pela desigualdade social e pelos esti-

${ }^{10}$ A VC é um movimento social transnacional que coordena organizações rurais, grupos de pequenos e médios produtores, movimentos de jovens e mulheres rurais, comunidades indígenas, movimentos de pessoas que não têm acesso à terra produtiva (os sem-terra) e de associações de trabalhadores agrícolas migrantes. Ela se autodenomina um movimento social de natureza autônoma, plural, independente, sem fins lucrativos, sem afiliação política ou partidária. É composta por oitenta organizações do campo, de todos os continentes (incluorganizaçóes do campo, de todos os continentes (inclu-
sive a América Latina), em um total de cinqüenta e sete países, segundo dados de julho de 2007. A VC pretende representar a voz camponesa no sistema internacional, participando da estrutura da FAO e buscando ter uma presença cada vez mais marcante nos protestos e coalizões sociais organizadas durante os encontros da OMC, do FMI ou do Banco Mundial, assim como no âmbito do Fórum Social Mundial (Milani, 2008). 
los de vida, bem como a necessidade de rever os modos de produção ultrapassam as fronteiras nacionais, gerando conflitos cuja solução política implica forçosamente a negociação multilateral entre os atores governamentais, econômicos e sociais (Sachs, 1994). Os problemas ambientais, do local ao global, têm um impacto sobre a definição da segurança coletiva (aquecimento). Eles colocam em questão um conjunto de princípios fundamentais da ordem mundial contemporânea: as fronteiras administrativas dos Estados nacionais, a separação entre o nacional e o internacional, a definição monolítica do interesse nacional, a ação estatal baseada na razão de Estado, assim como a soberania incondicionada dos Estados. A problemática ambiental perturba, assim, o mundo moderno da territorialidade contínua e justaposta. Como afirma Porto Gonçalves (2001, p.71-72):

Se o conceito de espaço vital foi tão essencial na época de F. Ratzel, como para dar sustentabilidade ao desenvolvimento calcado no Estado nacional [...] em um capitalismo mundializado o espaço vital necessário para dar sustentabilidade ao sistema já não é o Estado nacional. [...] Estamos frente a uma clara tensão de territorialidades dentro do processo atual de reorganização social, em que a questão ambiental, ou seja, a relação entre a sociedade e a natureza, cumpre um papel constituinte.

Mais do que isso, em muitos casos - quando pensamos no agravamento dos impactos negativos sobre o ambiente biofísico e humano causados por projetos no campo nuclear, construção de barragens e hidroelétricas, exploração de minérios, pesquisas sobre biodiversidade (e suas relações com a "biopirataria"), uso de transgênicos e de praguicidas na agricultura, por exemplo -, a resistência de redes e movimentos latino-americanos atua contra o Estado, podendo, eventualmente, contar com aliados situados no interior do aparelho estatal. Como lembra Martinez-Alier (2007), existe freqüentemente, em vários países latinoamericanos, uma pauta de cooperação entre as altas posições estatais e as empresas privadas estrangeiras quanto à utilização dos recursos naturais no interior do território nacional, como no caso da Bolívia que, em 2003, viu o seu governo promover um acordo com a corporação Repsol-YPF, a fim de exportar gás a preço baixo para a Califórnia. Esse acordo despertou a insurreição popular e a resistência de sindicatos, movimentos indígenas e alguns líderes políticos.

Torna-se evidente, assim, que confrontos dessa natureza desafiam a política ambiental institucionalizada dos ministérios, a legislação nacional e seus programas de monitoramento ecológico. O caso dos transgênicos no Rio Grande do Sul (Brasil), denunciado e combatido pelo Movimento dos Sem Terra, Pastoral da Terra, Via Campesina e Confédération Paysanne desde 1999, mas também o que se refere à autorização dada pelo Ministério do Meio Ambiente da Colômbia para que a Occidental Petroleum desenvolvesse a exploração petrolífera, nos anos 1990, em pleno território dos povos u'was (cujos direitos são reconhecidos pela constituição colombiana), ilustram as contradições crescentes entre Estado, movimentos sociais e industrialização da agricultura.

No entanto, sem incorrer na armadilha de uma análise exclusivamente construtivista dos discursos (o que contradiria as origens da ecologia política), é importante lembrar uma outra dimensão do território, que vai além da materialidade objetiva do desenvolvimento dos processos produtivos. A crise ecológica contribui igualmente para evidenciar a expansão da idéia de multiterritorialização (Haesbaert, 2006). Na modernidade, os territórios são construídos pelo sujeito nacional em suas relações com o Estado na qualidade de territórioszonas (fixos, enquadrados, hierarquizados). $\mathrm{Na}$ modernidade avançada, os novos territórios são territórios-redes (descontínuos, fragmentados, simultâneos). São esses territórios-redes que servem de suporte ao crescimento do ativismo ecológico transnacional na América Latina, à entrada no cenário político de projetos que envolvem atores múltiplos do Norte e do $\mathrm{Sul}^{11}$ e, como já afirmara

${ }^{11}$ Como afirmou Durkheim, à medida que avançamos na história, veremos que uma organização que se funda sobre agrupamentos territoriais (aldeias, vilas, distritos, províncias) se tornará cada vez menos importante; sem dúvida, pertencemos todos a uma comuna, a um departamento, mas esses laços que nos unem serão cada vez mais frágeis e mais fluídos. Essas divisões geográficas serão majoritariamente artificiais e não despertarão em nós sentimentos profundos. O espírito provincial terá 
Viola (1992), para a institucionalização multissetorial do ambientalismo nos anos 1990 ou, como prefere Porto Gonçalves (2001, p.76), para a transferência do terreno da ação coletiva do exclusivamente nacional a uma nova "territorialidade planetária”.

\section{Temporalidade}

O tempo ecológico intervém na política transnacional de diferentes maneiras: por meio da definição de solidariedades diacrônicas entre as gerações (proteger o meio ambiente hoje com o propósito de garantir as condições mínimas de desenvolvimento para as gerações futuras), pela definição de prioridades políticas e de recursos para resolver as crises ambientais (o tempo geológico do meio ambiente é diferente do curto prazo dos mandatos da democracia representativa), ou ainda por meio da necessidade de internalização dos custos econômicos pelas empresas (a competitividade e a produtividade dos mercados que funcionam na base do curto prazo, em contradição com as projeções futuras e os custos associados às mudanças de modelos tecnológicos).

É evidente que, nesse contexto, a questão ambiental impõe uma negociação política entre os interesses em conflito, perfilando-se como uma denúncia do 'laissez-faire' típico do liberalismo econômico: o horizonte temporal do economista não ultrapassa os dez ou vinte próximos anos (ou as próximas semanas para o mercado acionário), ao passo que o horizonte temporal da natureza se dá em termos de décadas ou mesmo de séculos. Daí resulta, hoje, a necessidade de se fazerem arbitragens políticas no que tange à definição dos bens

desaparecido de forma definitiva; o patriotismo de paróquia se tornará um arcaísmo que não poderá mais ser restaurado (Durkheim apud Haesbaert, 2006, p.23). Isso não quer dizer que as circunstâncias territoriais fixas estão predeterminadas a desaparecer completamente da política contemporânea, tendo em conta que as instituições antigas não desaparecem do dia para a noite frente às novas agências que surgem. $\mathrm{O}$ antigo sempre deixa seus vestígios. Entretanto, a organização política e social, de fundamento territorial e espacial exclusivo, coexiste com novas formas e conteúdos de reterritorialização, notadamente aquelas relativas às solidariedades transnacionais em torno da ecologia política. a proteger, dos mecanismos a serem implementados para a sua preservação, além dos meios e recursos financeiros a serem disponibilizados. Um ponto fundamental, mas altamente complexo, diz respeito a que tais decisões devem ser tomadas na ausência de certezas e de definições claras das conseqüências das degradações ecológicas. De fato, não há consenso científico que sirva de fundamento absoluto às decisões políticas; há muitas incertezas quanto aos impactos futuros (D’Amato, 1990; Sachs, 1994). A problemática ecológica é marcada por incerteza e imprevisibilidade, o que aumenta de forma significativa os riscos econômicos e as tensões políticas.

\section{Identidades e representações sociais}

A terceira categoria de análise diz respeito às múltiplas identidades e representações sociais do meio ambiente na construção dos problemas ecológicos que contam na agenda política contemporânea. As construções individuais e coletivas do ambientalismo se distinguem em função das representações do tempo, do espaço, da sociabilidade e, ao mesmo tempo, das normas aplicáveis à solução dos problemas coletivos (Comolet, 1991). Por exemplo, o meio ambiente pode ser concebido como momento harmonioso, mítico e a-histórico, como polaridade voltada para um futuro incerto, marcado pela atividade humana, ou ainda como um meio ambiente que consagra um sonho passado, tal como um verdadeiro ‘jardim do Éden'. Essas diferentes representações sociais são fundamentais no processo político e econômico de tomada de decisões, seja no nível dos governos, seja no nível da sociedade e dos indivíduos (Lascoumes, 1994).

Nesse sentido, o meio ambiente é antes visto como uma construção social: ele não é nem um bem pré-existente, nem um patrimônio a-histórico, nem uma entidade dotada de uma essência atemporal. O meio ambiente é uma natureza trabalhada pela política: é um produto da história. A tradução da representação em problema político pode ser compreendida como uma atividade que 
compõe a agenda (agenda setting); pode ocorrer por meio da prática da mídia e do setor privado, da ação político-administrativa, ou por meio da ação associativa e cidadã, revelando, assim, o caráter intersetorial e pluridimensional da ecologia. A democratização do conhecimento dos problemas do meio ambiente e das escolhas econômicas, tecnológicas e sociais que surgem desse processo nos guiam pouco a pouco para a constituição de um público mais ampliado, indispensável para a concretização de soluções democráticas para os problemas ecológicos.

Sem dúvida alguma, o meio ambiente integra, então, o espaço público de discussão internacional latino-americano. Pelo viés das solidariedades transnacionais, os movimentos e redes ecologistas são novos atores políticos que promovem uma desconstrução da exclusividade da cidadania nacional, ao projetar os fundamentos de uma idéia de "cidadania planetária" (Morin; Kern, 1993). Ademais, os movimentos sociais podem reconfigurar suas identidades e integrar valores da ecologia política, como no caso dos seringueiros da Amazônia brasileira que, segundo Porto Gonçalves (2001, p.213), transitam da identidade econômica de profissionais da exploração da borracha a outra, de cunho político e sociocultural, de protetores dos interesses da floresta.

\section{CONCLUSÃO}

O campo do ambientalismo coloca para a ação política, na América Latina, a necessidade de superar pelo menos três dilemas: entre soberania e interdependência, entre globalização neoliberal e promoção dos bens comuns, assim como o dilema entre os interesses locais/nacionais particulares e os interesses regionais/supranacionais coletivos. Parafraseando Badie (1995), a problemática ambiental põe em evidência a hipótese da "soberania perdida”, vez que impõe o princípio de responsabilidade na ação política transnacional. Ao trazer esse princípio ético e político para o plano das relações internacionais, é importante ter em conta o Estado e seu sistema interestatal, mas, principalmente, é fundamental levar em consideração as autoridades superpostas (Mercado, agências internacionais e Estados), as lealdades múltiplas e a noção de soberania condicionada (pelo capital e pela política da natureza). Se, na modernidade, as comunidades de pertencimento (a topofilia da política) se desenvolveram em torno do Estado, o campo do ambientalismo renovado nas redes antialterglobalistas mostra que novas comunidades de consciência se desenvolvem externamente às contradições estatais, sem levar sempre e exclusivamente em conta as fronteiras do Estado e as nacionalidades. Para que a esfera pública, originalmente conceituada de forma co-extensiva à comunidade política soberana estatal, seja re-politizada e faça sentido para os cidadãos (permitindo, uma vez mais, questionamentos sobre igualdade, paridade, reconhecimento, inclusão e participação), é necessário conceber a formação das opiniões públicas e a constituição de interlocutores políticos para além dos limites e dos parâmetros de Westphalia, constituindo o que Nancy Fraser denomina de "modelo pós-Westpaliano de soberania desagregada" (Fraser, 2007, p. 55). Enfim, retomando Rosenau (1992) e sua noção de um "mundo multicentrado", os transnacionalismos engendrados pela crise ecológica na América Latina ganham forma graças, também, à ação dos indivíduos mais informados e com maior aptidão para agir no mundo da política mundial - os skillfull individuals de James Rosenau. Os sujeitos, na modernidade avançada, têm uma base de lealdade que é igualmente territorializada (são cidadãos de um Estado), mas colocam em cena múltiplas formas de solidariedade e afiliação política que lhes permitem uma reterritorialização na qualidade de ecologistas e defensores de um ideal de cidadania planetária.

(Recebido para publicação em junho de 2008) (Aceito em agosto de 2008) 


\section{REFERÊNCIAS}

ACSELRAD, H. Conflitos ambientais no Brasil. Rio de Janeiro: Relume Dumará, 2004. 294 p.

- PADUA, J. A.; HERCULANO, S. (Org.). Justiça ambiental e cidadania. Rio de Janeiro: Relume Dumará, 2004, 315 p.

ANDRADE, J. Célio S.; TARAVELLA, Romain. Le rôle du secteur privé dans la gouvernance internationale de l'environnement: de "rule-taker" à "rule-maker"? In: EADI GENERAL CONFERENCE GLOBAL GOVERNANCE FOR SUSTAINABLE DEVELOPMENT, $12^{\text {th }}$, Genebra, 2008 Proceedings. Genebra, 2008.

BADIE, Bertrand. La fin des territoires, essai sur le désordre international et sur l'utilité sociale du respect. Paris: Fayard, 1995. (Collection l'espace du politique).

BARROS-PLATIAU, A. F. Atores não-estatais em regimes internacionais ambientais: turbulência ou governança global?. In: CARVALHO, M.I.V. de; SANTOS, M. H. de C. (Org.). O século 21 no Brasil e no mundo. Bauru: EDUSC, 2006. v. 1, p.209-236.

BECKERMAN. Wilfred. Sustainable development: is it a useful concept? Environmental Value, [S.l.], v. 3, n. 3, p. 191-209, 1994.

BRENTON, Tony. Theg greening of machiavelli. London: Earthscan, 1994

CALDWELL, Lynton. International environmental policy, emergence and dimensions. Durham: Duke University Press, 1984

CAIRO, Heriberto. The duty of the benevolent master: from sovereignty to suzerainty and the biopolitics of Intervention. Alternatives, [S.l.], v. 31, p. 285-311, 2006

CHESNAIS, François; SERFATI, Claude. Ecologia e condições físicas de reprodução social: alguns fios condutores marxistas. Crítica Marxista, São Paulo. Boitempo, n.16, p.39-75, 2003.

COMOLET, Arnaud. Le renouveau écologique: de l'écoutopie à l'écocapitalisme. Futuribles, Paris, p. 41-54, set. 1991.

COSTANZA, Robert (Org.). Ecological economics: the science and management of sustainability. New York: Columbia University Press, 1991.

$\therefore$ DALY, Herman; COBB, J. For the common good: redirecting the economy toward community, the environment and a sustainable future. Boston: Beacon Press, 1989.

D’AMATO, Anthony. What obligation does our generation owe to the next? An approach to global environmenta responsibility. American Journal of International Law, New York, v. 84, n. 1, jan., p. 190-213, 1990.

DELEAGE, Jean-Paul. Ecologie: les nouvelles exigences

DELLA PORTA, Donatella: TARROW, Sidney (Org.) Transnational protest and global activism. New York;
Toronto;Oxford: Rowman and Littlefield Publishers, 2005.

DIAS, C. C.; COSTA, M. C. Repartição de benefícios em pesquisa: um olhar a partir dos projetos de bioprospecção. In: ESOCITE: Jornadas Latino-Americanas de Estudos Sociais da Ciência e das Tecnologias, 7. Rio de Janeiro, 2008. Anais... Rio de Janeiro, 2008.

FRASER, Nancy. Transnationalizing the public sphere: on the legitimacy and efficacy of public opinion in a postWestphalian world. In: BENHABIB, Seyla; SHAPIRO, Ian; PETRANOVIC, Danilo (Org.). Identities, affiliations, and allegiances. Cambridge: Cambridge University Press,
2007. p. 45-66.

HAESBAERT, Rogério. O mito da desterritorialização - do fim dos territórios à multiterritorialidade. Rio de Janeiro: Bertrand Brasil, 2006.

LASCOUMES, Pierre. L'eco-pouvoir, environnements et politiques. Paris: La Découverte, 1994. (Série ecologie et société)

LATOUR, Bruno. Politiques de la nature, comment faire entrer les sciences em démocratie. Paris, La Découverte, 1999.

LEIS, Héctor et al. Ecologia e política mundial. Rio de Janeiro: Vozes/FASE/AIRI/PUC-RIO, 1991

MARTINEZ-ALIER, Joan. O ecologismo dos pobres. São Paulo: Ed. Contexto, 2007.

MILANI, Carlos R. S. O meio ambiente e a regulação da ordem mundial. Contexto Internacional, Rio de Janeiro, v. 20 , n. 2, p. 303-347, 1998.

Governança global e meio ambiente: como compatibilizar economia, política e ecologia. Governança global, reorganização da política em todos os níveis de ação. São Paulo: Fundação Konrad Adenauer, 1999. p.97128. (Série pesquisas, n. 16)

La complexité dans l'analyse du système-monde: l'environnement et les régulations mondiales. Le Revue Droit et Société, Paris, n. 46, p. 425-455, 2000.

Contestación política y movimientos sociales transnacionales en América Latina: el caso de Vía Campesiana. In: CAIRO, Heiberto; DE SIERRA, Gerônimo (Org.). América Latina, una y diversa: teorías y métodos para su análisis. San José, Costa Rica: 2008.

; LANIADO, Ruthy Nadia. Transnational social movements and the globalization agenda: a methodological approach based on the analysis of the World Social Forum. Brazilian Political Science Review, [S.l.] v. 1, n. 2, p.10-39. 2007a.

Solidarités environnementales, contestation transnationale et renouvellement de la politique mondiale. Lien Social et Politiques, Montreal, RIAC, n. 58, p. 133-144. 2007b.

MORIN, Edgar ; KERN, Anne Brigitte. Terre patrie. Paris: Editions du Seuil, 1993

O'CONNOR, James. Is capitalism sustainable?, In: MARTIN O'Connor (Org.), Is capitalism sustainable? Political economy and the politics of ecology. New York: Gilford Press, 1994.

PORTO GONÇALVEZ, Carlos Walter. Geografías, movimientos sociales, nuevas territorialidades sustentabilidad. México D. F.: Siglo XXI Ediciones, 2001.

PRADES, José A. Global Environmental change and contemporary society: classical sociological analysis revisited. International Sociology, London, Sage, v. 14, n. 1, p. 7-31, 1999.

REDCLIFT, Michael; SAGE, Colin. Global environmental change and global inequality, North/South perspectives. International Sociology, London, Sage, v. 13, n. 4, p. 499516, 1998.

REZENDE, Enio Antunes. Biopirataria ou bioprospecção? Uma análise crítica da gestão do saber tradicional no Brasil. 2007. Tese (Doutorado) - Escola de Admnistração da UFBA, 2007

ROSA, Eugene A; DIETZ, Thomas. Climate Change and Society: speculation, construction and scientific investigation. International Sociology, London, Sage, v. 13, n. 4, p. 421-455, 1998.

ROSENAU, James N. Governance, Order, and change in world politics. In: ; CZEMPIEL, Ernst-Otto (Org.) 
Governance without government: order and change in world politics. Cambridge: Cambridge University Press, 1992. p. 1-29.

SACHS, Ignacy. Le défi de l'environnement. In SALOMON, Jean-Jacques et al. La quête incertaine science, technologie, développement. Washington,D.C.: United Nations: University Press e Economica, 1994. p. 321-361.

SMOUTS, Marie-Claude. As novas relacões internacionais: práticas e teorias. Brasília: Editora da UnB, 2004

SOUSA SANTOS, Boaventura. 2006. A gramática do tempo, para uma nova cultura política. São Paulo: Cortez Ed., 2006.
TEIVANEM, Teivo. Twenty-two theses on the problems of democracy in the World Social Forum, Library of Alternatives. Disponível em: www.forumsocialmundial.org.br Acesso em: 15 nov., 2004.

VIOLA, Eduardo J. O movimento ambientalista no Brasil (1971-1991): da denúncia e conscientização pública para a institucionalização e o desenvolvimento sustentável. In: GOLDENBERG, M. (Org.). Ecologia, ciência e política. Rio de Janeiro, Revan, 1992.

WALLERSTEIN, Immanuel. The dilemmas of open space: the future of the World Social Forum. International Social Science Journal, [S.l.], n. 182, dez., 2004.

\section{POLITICALECOLOGY, ENVIRONMENTALIST MOVIMENTS AND TRANSNATIONAL CONTESTATION IN LATIN AMERICA}

\section{Carlos R. S. Milani}

In the aftermath of the Cold War, there has been a renewal in the Latin American academic debate on tensions between environmental protection, ethics and international politics. Those who defend the idea that international relations stem from an exclusive interaction between sovereign and independent political entities are confronted with those who reaffirm the relevance of many other players beyond the state in the global ecopolitics. That means that the tenets of unconditioned sovereignty and non-intervention, which have traditionally built the sense of 'international relations', are questioned by the growing transnationalization of political demands by environmental movements in favor of ethical and responsible patterns of action and behavior. Rooted in these premises, the present article is structured in two parts: (1) a discussion on the process of internationalization of the environmental problematique, and contemporary tensions between environment, ethics, and international politics in Latin America; (2) an analysis of political demands by Latin American environmental movements associated with transnational antiglobalization contention in the World Social Forum.

KEYWORDS: political ecology, environmental movements, transnational contention, international relations, Latin America.

\section{L'ÉCOLOGIE POLITIQUE, LES MOUVEMENTS ENVIRONNEMENTAUXETLACONTESTATION TRANSNATIONALE ENAMÉRIQUE LATINE}

\author{
Carlos R. S. Milani
}

Les années de l'après-Guerre Froide ont permis le renouvèlement du débat latino-américain sur les tensions entre l'environnement, l'éthique et la politique internationale. Les défenseurs de l'idée selon laquelle les relations internationales émergent exclusivement de l'interaction entre des entités politiques souveraines et indépendantes s'opposent à ceux qui soutiennent l'importance de bien d'autres acteurs outre l'Etat sur la scène écopolitique mondiale. Autrement dir, les principes de la souveraineté inconditionnée et de la non-ingérence (qui ont traditionnellement construit le sens des «relations internationales ») sont remis en cause par une croissante transnationalisation des revendications politiques des réseaux et des mouvements écologistes en faveur de conduites éthiques et responsables à l'égard de l'environnement planétaire. Partant de ces présupposés, cet article se structure en deux parties: (1) une discussion concernant le processus d'internationalisation de la problématique écologique et des tensions contemporaines entre l'environnement, l'éthique et la politique internationale en Amérique Latine; (2) une analyse des questions soulevées par les réseaux de mouvments écologistes latino-américains agissant au cœur de la contestation transnationale du Forum Social Mondial.

MoTS-CLÉS: ecologie politique, mouvements écologistes, contestation transnationale, relations internationales, Amérique Latine. 